\title{
Intravenous thrombolysis: Still an important tool in the management of severe ischemic stroke patients
}

Stroke continues to be the second leading cause of death worldwide. This mortality burden has come with more than a doubling of the stroke incidence in low- and middle-income countries, surpassing the incidence rates observed in most high-income countries. Stroke is also the leading cause of death and accounts for 1 in 7 deaths in a rural community in Gadchiroli, one of the most backward districts of India. There is high early mortality because of stroke and stroke is emerging as a public health priority in rural India. ${ }^{[1]}$

In this issue of Journal of Neurosciences in Rural Practise, Dharmasaroja and Muengtaweepongsa ${ }^{[2]}$ describe the results of a retrospective case-control study comparing the outcomes of patients with acute moderate to severe ischemic strokes (The National Institutes of Health Stroke Scale [NIHSS] score of $\geq 15$ ) with and without intravenous recombinant tissue plasminogen activator (rtPA) thrombolysis treatment. From January 2011 to May 2014, 240 patients with clinical deficits suggestive of anterior circulation large vessel occlusion and presentation to the Thammasat University Hospital within $24 \mathrm{~h}$ after symptom onset were included to the study. Computed tomography (CT) imaging was performed at admission and intravenous rtPA was initiated to 120 eligible patients within $4.5 \mathrm{~h}$ time window. In contrast, 120 patients were not treated with rtPA mainly due to CT demonstrated extensive early ischemic changes. Intravenous thrombolysis improved functional outcome at 90 days, with more patients achieving functional independence (39\% vs. $17 \%)$. In addition, mortality was higher among patients who did not receive rtPA treatment (51\% vs. $16 \%)$ and there was no sign of increased bleeding risk in the rtPA group (6\% vs. $4 \%)$.

Unfavorable outcomes with up to $41 \%$ mortality rate at 3 months have been previously reported regarding the natural history of proximal intracranial arterial occlusions with a baseline NIHSS score of 10 or higher. ${ }^{[3]}$ In addition, despite intravenous thrombolysis within $3 \mathrm{~h}$ time window in patients with hyperacute internal carotid artery or proximal M1 segment of the middle cerebral artery (MCA) occlusion with a median NIHSS score of 18 , there was a significant decrease in functional independency (18\% vs. $71 \%$ ) and increase in mortality ( $32 \%$ vs. $3 \%$ ) compared to a more distal occlusion with a median NIHSS score of $11 .{ }^{[4]}$ However, there is a greater benefit of intravenous thrombolysis compared to placebo in patients with increasingly severe strokes (NIHSS score of $\geq 15$ ). ${ }^{[5]}$

In most instances, nonenhanced CT will provide the necessary information to make decisions about the use of rtPA treatment in hyperacute ischemic stroke. A structured scoring system, such as the Alberta Stroke Program Early CT Score (ASPECTS) can quantify the extent of early ischemic changes in the MCA territory. In addition, the accuracy of the ASPECTS is markedly improved by the optimization of the window width and center level settings or by the use of CT angiography source images. ${ }^{[6]}$ An ASPECTS of $\leq 5$ can be used as a guideline when evaluating $>1 / 3$ of the region of territory involvement, a contraindication to intravenous thrombolysis. ${ }^{[7]}$ In contrast, if endovascular therapy for hyperacute ischemic stroke is considered, ASPECTS score of $\geq 6$ is required, and a noninvasive intracranial vascular study is strongly recommended already during the initial imaging evaluation. However, for patients who qualify for intravenous rtPA, initiating intravenous rtPA before noninvasive vascular imaging is recommended for patients who have not had noninvasive vascular imaging as part of their initial imaging assessment for stroke. In addition, endovascular therapy with a stent retriever requires the patient to be at an experienced stroke center with rapid access to cerebral angiography, general anesthesia with intubation (if needed), and qualified neurointerventionalists within $6 \mathrm{~h}$ of symptom onset. The benefits of additional imaging such as CT perfusion, including measures of infarct core, collateral flow status, and penumbra, for selecting patients for acute reperfusion therapy, is still unknown. ${ }^{[8]}$

The use of intravenous thrombolysis with rtPA for hyperacute anterior circulation ischemic stroke is associated with improved outcomes for a broad spectrum of patients, who can be treated within $3 \mathrm{~h}$ of symptom onset and for a more selective spectrum of patients who can be treated between 3 and $4.5 \mathrm{~h}$ after symptom onset. Ultimately, mortality and disability burden related to 
hyperacute moderate to severe ischemic strokes can be safely decreased with management of eligible patients with intravenous rtPA when treatment is provided by acute stroke-ready hospital that has made an institutional commitment to evaluate, diagnose, and treat ischemic stroke patients effectively and efficiently.

\section{Jukka T. Saarinen}

Department of Neurology, Vaasa Central Hospital, Vaasa, Finland

Address for correspondence: Dr. Jukka T. Saarinen, Hietalahdenkatu 2-4, 65130 Vaasa, Finland. E-mail: jukka.saarinen@vshp.fi

\section{References}

1. Kalkonde YV, Deshmukh MD, Sahane V, Puthran J, Kakarmath S, Agavane $\mathrm{V}$, et al. Stroke is the leading cause of death in rural Gadchiroli, India: A prospective community-based study. Stroke 2015;46:1764-8.

2. Dharmasaroja PA, Muengtaweepongsa S. Outcomes of patients with large middle cerebral infarct treated with and without intravenous thrombolysis. J Neurosci Rural Pract 2016;7:36-9.

3. Lima FO, Furie KL, Silva GS, Lev MH, Camargo EC, Singhal AB, et al. Prognosis of untreated strokes due to anterior circulation proximal intracranial arterial occlusions detected by use of computed tomography angiography. JAMA Neurol 2014;71:151-7.

4. Saarinen JT, Sillanpää N, Rusanen H, Hakomäki J, Huhtala H, Lähteelä A, et al. The mid-M1 segment of the middle cerebral artery is a cutoff clot location for good outcome in intravenous thrombolysis. Eur J Neurol 2012;19:1121-7.

5. IST- Collaborative Group, Sandercock P, Wardlaw JM, Lindley RI, Dennis M, Cohen G, et al. The benefits and harms of intravenous thrombolysis with recombinant tissue plasminogen activator within $6 \mathrm{~h}$ of acute ischaemic stroke (the third international stroke trial [IST-3]): A randomised controlled trial. Lancet 2012;379:2352-63.

6. Arsava EM, Saarinen JT, Unal A, Akpinar E, Oguz KK, Topcuoglu MA. Impact of window setting optimization on accuracy of computed tomography and computed tomography angiography source image-based Alberta stroke program early computed tomography score. J Stroke Cerebrovasc Dis 2014;23:12-6.

7. Demchuk AM, Hill MD, Barber PA, Silver B, Patel SC, Levine SR; NINDS rtPA Stroke Study Group, et al. Importance of early ischemic computed tomography changes using ASPECTS in NINDS rtPA stroke study. Stroke 2005;36:2110-5.

8. Powers WJ, Derdeyn CP, Biller J, Coffey CS, Hoh BL, Jauch EC, et al. 2015 AHA/ASA focused update of the 2013 guidelines for the early management of patients with acute ischemic stroke regarding endovascular treatment: A guideline for healthcare professionals from the American Heart Association/American Stroke Association. Stroke 2015. pii: STR.0000000000000074.

This is an open access article distributed under the terms of the Creative Commons Attribution-NonCommercial-ShareAlike 3.0 License, which allows others to remix, tweak, and build upon the work non-commercially, as long as the author is credited and the new creations are licensed under the identical terms.

\begin{tabular}{|l|l|}
\hline \multicolumn{2}{|c|}{ Access this article online } \\
\hline Quick Response Code: & Website: \\
\hline & www.ruralneuropractice.com \\
\cline { 2 - 3 } & \\
\hline & \\
\hline
\end{tabular}

How to cite this article: Saarinen JT. Intravenous thrombolysis: Still an important tool in the management of severe ischemic stroke patients. J Neurosci Rural Pract 2016;7:1-2.

\section{"Quick Response Code" link for full text articles}

The journal issue has a unique new feature for reaching to the journal's website without typing a single letter. Each article on its first page has a "Quick Response Code". Using any mobile or other hand-held device with camera and GPRS/other internet source, one can reach to the full text of that particular article on the journal's website. Start a QR-code reading software (see list of free applications from http://tinyurl.com/ yzlh2tc) and point the camera to the QR-code printed in the journal. It will automatically take you to the HTML full text of that article. One can also use a desktop or laptop with web camera for similar functionality. See http://tinyurl.com/2bw7fn3 or http://tinyurl.com/3ysr3me for the free applications. 